\title{
Caries Detection Methods Based on Changes in Optical Properties between Healthy and Carious Tissue
}

\author{
Lena Karlsson \\ Division of Cariology, Department of Dental Medicine, Karolinska Institutet, Box 4064, 14104 Huddinge, Sweden \\ Correspondence should be addressed to Lena Karlsson, lena.karlsson@ki.se
}

Received 29 October 2009; Accepted 4 February 2010

Academic Editor: Alexandre R. Vieira

Copyright () 2010 Lena Karlsson. This is an open access article distributed under the Creative Commons Attribution License, which permits unrestricted use, distribution, and reproduction in any medium, provided the original work is properly cited.

A conservative, noninvasive or minimally invasive approach to clinical management of dental caries requires diagnostic techniques capable of detecting and quantifying lesions at an early stage, when progression can be arrested or reversed. Objective evidence of initiation of the disease can be detected in the form of distinct changes in the optical properties of the affected tooth structure. Caries detection methods based on changes in a specific optical property are collectively referred to as optically based methods. This paper presents a simple overview of the feasibility of three such technologies for quantitative or semiquantitative assessment of caries lesions. Two of the techniques are well-established: quantitative light-induced fluorescence, which is used primarily in caries research, and laser-induced fluorescence, a commercially available method used in clinical dental practice. The third technique, based on near-infrared transillumination of dental enamel is in the developmental stages.

\section{Introduction}

Dental caries is one of the most prevalent chronic diseases of humans worldwide. When different stages of the disease are taken into account, from the initial to the clinically manifest lesion, very few individuals are truly unaffected. In most industrialised countries $60 \%-90 \%$ of school-aged children are affected. The prevalence among adults is even higher and in most countries the disease affects nearly $100 \%$ of the population [1].

During the last thirty years, however, major changes have occurred in the pattern of the disease. Progression of enamel caries is now slower [2], allowing time for preventive intervention before irreversible destruction of tooth substance occurs. During the early stages of the disease the process is reversible and can be arrested: noninvasive intervention can convert a lesion from an active to an inactive state $[3,4]$. Appropriate diagnostic techniques are necessary to support such decisions about management of the individual lesion. The clinician needs to be able to monitor the outcome of noninvasive measures and in cases where there is evidence of lesion progression, make a timely decision to intervene, using minimally invasive techniques and restoring damaged tooth structure without weakening the tooth. Applying strategies to control, arrest, or reverse the disease process can reduce the economic burden, pain, and suffering of placing and replacing restorations [5].

This modern, conservative approach to clinical management of dental caries, which has been evolving during the past twenty years, has necessitated a critical appraisal of methods used today for clinical detection of carious lesions.

Complementing traditional diagnostic methods with advanced, more sensitive methods will improve caries diagnostic routines and hence the dental care and treatment of patients. The application of such complementary methods should offer objective information about the presence and severity of a lesion, to complement the clinician's subjective interpretation, providing evidence-based clinical caries diagnosis. In this context, there is also a place for more sensitive caries detection methods in clinical caries research. Clinical trials in which lesions are monitored in thousands of subjects over several years are no longer commercially viable. A quantitative method capable of measuring small changes would allow trials of much shorter duration and fewer subjects $[6,7]$.

Conventional examination for caries detection is based primarily on subjective interpretation of visual examination and tactile sensation, aided by radiographs. The clinician 
makes a dichotomous decision (absence or presence of a lesion) based on subjective interpretation of colour, surface texture, and location, using rather crude instruments such as a dental explorer and bitewing radiographs [8]. Studies based on these methods often show low sensitivity and high specificity, that is, a large number of lesions may be missed [9-13]. Sensitivity and specificity are widely used measures to describe and quantify the diagnostic ability of a test [14]. In the context of caries research, sensitivity is a measure of the method's ability to correctly identify all surfaces damaged by caries, and specificity the measure of correctly identified all sound surfaces. Sensitivity and specificity are expressed as values between 0 and 1 (100\%), values closer to 1 indicating a high quality result. For caries diagnostic methods, values should be at least 0.75 for sensitivity and over 0.85 for specificity [15].

Diagnostic techniques are also evaluated in terms of validity and reliability. To determine validity, the outcome as measured by the method is compared with a reference standard, a "true" situation. Reliability expresses the consistency of a set of measurements performed with the method. High validity is considered to confirm the absence of systematic errors and high reliability the absence of random errors of the method. The generalisability of a diagnostic technique is also described in terms of external and internal validity. The external validity reflects the extent to which the results of a study can be extrapolated to other subjects or settings, whereas internal validity reflects the degree to which conclusions about causes or relationships are likely to be true, in view of the measures used, the research setting, and the overall study design. Good experimental design will filter out the most confounding variables, which could compromise the internal validity of an experiment.

A wide variation in terms of sensitivity and specificity for conventional caries detection methods are found in the literature $[9,16,17]$. An overall low sensitivity of less than 0.50 is reported, which means that a guess would provide the same result when we correctly want to identify a caries lesion. A recently published comprehensive review [15] stated that the evaluations of diagnostic performance are based on limited numbers of studies of questionable internal and external validity attributable to incomplete descriptions of selection and diagnostic criteria and observer reliability. The quality of published studies is further compromised by the use of small numbers of observers, nonrepresentative teeth, samples with high lesion prevalence, a variety of reference standards of unknown reliability, and variations in statistical analysis of the reported results.

It is apparent that conventional methods for the detection of dental caries do not fulfill the criteria for an ideal caries detection method. These methods rely on subjective interpretation and are insensitive to early caries detection. It is widely recognised that the current methods cannot detect caries lesions until a relatively advanced stage, involving as much as one-third or more of the thickness of enamel [18].

The shortcomings of conventional caries detection methods and the need for supplementary methods have long been acknowledged. The series of published proceedings from the three "Indiana Conferences on Early Detection of Dental
TABLe 1: Summary of optical caries detection methods.

\begin{tabular}{lc}
\hline Optical Coherence Tomography & OCT \\
Polarized Raman Spectroscopy & PRS \\
Polarization Sensitive Optical & \\
Coherence Tomography & PS-OCT \\
Fibre Optic Transillumination & \\
Quantitative Light-induced & FOTI and DiFOTI \\
Fluorescence & QLF \\
Laser-induced Fluorescence & LF \\
Transillumination with & TI-NIR \\
Near-Infrared light & \\
Infrared fluorescence & IR fluorescence \\
Near-Infrared reflectance & \\
imaging & NIR reflectance imaging \\
Terahertz Pulse Imaging & \\
Multiphoton imaging & TPI \\
Time-Correlated Single-Photon \\
Counting Fluorescence Lifetime \\
Imaging
\end{tabular}

Caries" contains a wealth of detail of work in this area [1921]. Over the past twenty years there has been intensive research into more sophisticated methods for early detection of dental caries [5, 7-9, 16, 17, 22-34]. There are a number of optical caries detection methods and some are summarized in Table 1. Several are in their infancy and there is significant work involved in developing these techniques. Therefore, validation studies are essential to determine their clinical utility before implementation in clinical practice.

An initial effect of the caries disease process, increased porosity, results in a distinct change in the optical properties of the affected dental tissue, providing objective evidence of a caries-induced change. Caries detection methods based on changes in a specific optical property are referred to in the literature as optically based methods, optical methods, or dental tissue optics. The methods are based on the measurement of a physical signal, derived from the interaction of light with dental hard tissue. The following section presents a brief description of the principles underlying these methods.

\section{Physical Principles Underlying Optical Caries Detection}

Optical caries detection methods are based on observation of the interaction of energy which is applied to the tooth, or the observation of energy which is emitted from the tooth [26]. Such energy is in the form of a wave in the electromagnetic spectrum (Figure 1). The caries detection methods described in this paper use light in the visible and near-infrared range (NIR).

In its simplest form, caries can be described as a process resulting in structural changes to the dental hard tissue. The diffusion of calcium, phosphate, and carbonate out of the tooth, the demineralisation process, will result in loss of mineral content. The resultant area of demineralised tooth substance is filled mainly by bacteria and water. The porosity 


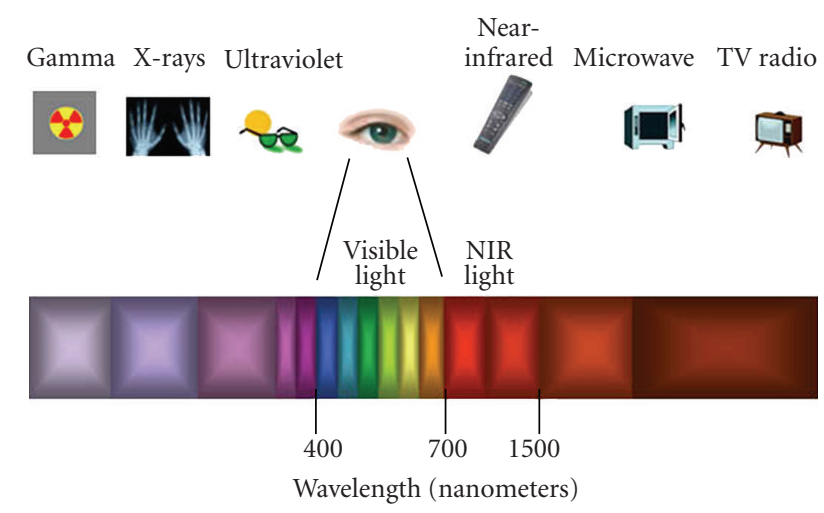

Figure 1: The electromagnetic spectrum. Wavelengths of interest in this paper are the visible light spectrum from $400 \mathrm{~nm}$ to $700 \mathrm{~nm}$ and the range of near-infrared light from $750 \mathrm{~nm}$ to $1500 \mathrm{~nm}$.

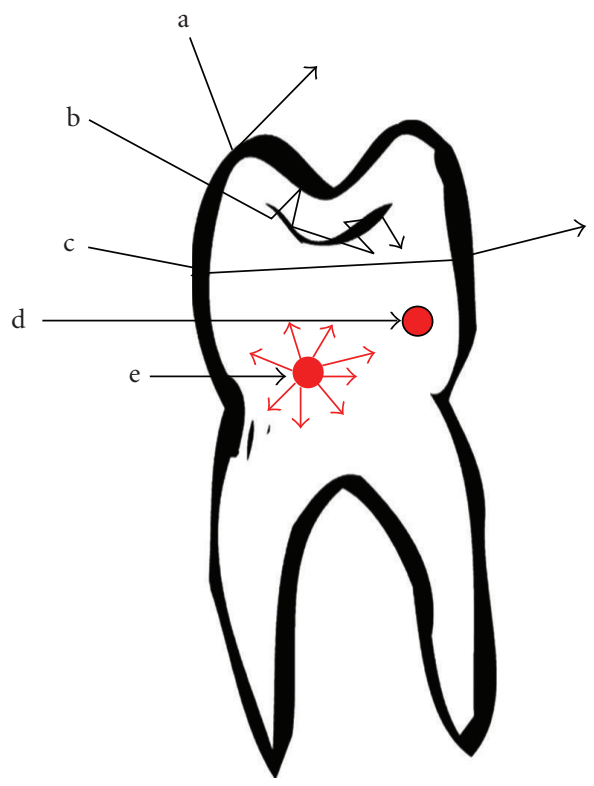

Figure 2: Light interactions with a tooth. How waves can interact with the dental hard tissue; (a) reflection, the wave rebounds; (b) scattering, the incident wave enters the tooth and changes direction. The photons then leave the tooth either as backscattering, where the photons leave through the surface by which they entered, or through another surface (scattering with diffuse transmission); (c) transmission, the wave is illuminated through the tooth and refracts on the surfaces; (d) absorption with heat production; (e) absorption with fluorescence. Most interactions of waves are a combination of these processes.

of this area is greater than that of the surrounding structure. Increased scattering of incident light due to this structural change appears to the human eye as a so-called white spot. Hence, the caries process leads to distinct optical changes that can be measured and quantified with advanced detection methods based on light that shines on and interacts with the tooth (Figure 2).
2.1. Scattering. Scattering is the process in which the direction of a photon is changed without loss of energy. The incident light is forced to deviate from a straight path when it interacts with small particles or objects in the medium through which the light passes. In physical terms scattering is regarded as a material property. A glass of milk is seen as white because incident light on the milk is scattered in all directions, leaving the milk without absorption [35]. Snow appears white because light incident in the snow is scattered in all directions by the small ice crystals. Light of all visible wavelengths exits snow without suffering absorption. Scattering is highly wavelength sensitive, shorter wavelengths scatter much more than longer ones [26]. Therefore, caries detection methods employing wavelengths in the visible range of the electromagnetic spectra $(400 \mathrm{~nm}$ to $700 \mathrm{~nm}$ ) are highly limited by scattering. An early enamel lesion looks whiter than the surrounding healthy enamel because of strong scattering of light within the lesion [23]. Methods measuring lesion severity are based on differences in scattering between sound and carious enamel.

2.2. Absorption with Fluorescence. Absorption is the process in which photons are stopped by an object and the wave energy is taken in by the object. The energy lost is mostly converted into heat or into another wave which has less energy and hence longer wavelengths. In physical terms absorption is also regarded as a material property. The previous analogy of the glass of milk appearing white can be extended to a cup of tea [35]; the tea is seen as transparent because it does not scatter light, but it looks brown because much of the light is absorbed by the tea. Likewise, mud and pollution in white snow can be seen as dark spots because certain wavelengths are absorbed by these polluted spots. Absorption of light in tissue is strongly dependent on the wavelength. Water is an example of a strong absorber in the infrared range. After absorption the energy can be released by emission of light at a longer wavelength, through the process of fluorescence. Fluorescence occurs as a result of the interaction of the wavelength illuminating the object and the molecule in this object. The energy is absorbed by the molecule with subsequent electronic transition to the next state, to a higher level state where the electrons remain for a short period of time. From here the electrons may fall back to the ground state and release the gained energy in terms of longer wavelength and colour, which is related to the energy given off and fluorescent light can be emitted. Autofluorescence, the natural fluorescence of dental hard tissue without the addition of other luminescent substances has been known for a long time [36]. Demineralisation will result in loss of autofluorescence [37] which can be quantified using caries detection methods based on the differences in fluorescence between sound and carious enamel.

\section{Optical Caries Detection Methods}

3.1. Quantitative Light-Induced Fluorescence. The quantitative light-induced fluorescence (QLF) is based on the principle that the autofluorescence of the tooth alters as the 
mineral content of the dental hard tissue changes. Increased porosity due to a subsurface enamel lesion scatters the light either as it enters the tooth or as the fluorescence is emitted, resulting in a loss of its natural fluorescence. Bjelkhagen et al., [38], Sundström et al., [39] and subsequently de Josselin de Jong et al. [40] developed a technique based on this optical phenomenon. The underlying theory has been described extensively in several publications [41-43]. The changes in enamel fluorescence can be detected and measured when the tooth is illuminated by violet-blue light (wavelengths $290-450 \mathrm{~nm}$, average $380 \mathrm{~nm}$ ) from a camera hand piece, following image capturing using a camera fitted with a yellow $520 \mathrm{~nm}$ high pass filter (QLF; Inspektor Research Systems, Amsterdam, the Netherlands) (Figure 3(a)). The image is captured, saved, and processed: it is first converted to black-and-white so that thereafter the lesion site can be reconstructed by interpolating the grey level values in the sound enamel around the lesion. The difference between measured and reconstructed values gives three quantities: $\Delta F$ (average change in fluorescence, $\%$ ), lesion area $\left(\mathrm{mm}^{2}\right)$, and $\Delta \mathrm{Q}($ area $\times \Delta F)$, which gives a measure of the extent and severity of the lesion. Changes in fluorescence radiance and lesion area can be followed over time, to measure lesion development. Figure 3(b) shows the analytical stages of the method.

A high positive correlation is reported between QLF and absolute mineral loss, $r=0.82-0.92$ [44-46]. At a consensus meeting in 2002, The International Consensus Workshop on Caries Clinical Trials (ICW-CCT) [47], it was agreed that QLF may offer one solution in the effort to reduce both the number of subjects and the duration of caries clinical trials. The method seems to have been rapidly adopted as a standard reference measure in clinical tests of the efficacy of preventive measures [42, 48-50]. Application for quantification of dental fluorosis [51], erosive lesions $[52,53]$, and staining, and bleaching of teeth [54-56] has been investigated. The QLF method can also measure and quantify the red fluorescence (RF) from microorganisms in plaque [57]. The RF observed in plaque can be of use when monitoring oral hygiene, denture plaque assessment, removing infected dentin, and detecting a leaking sealant or caries at the margin of a restoration. Two quantities are obtained, $\Delta R$ (average change in red fluorescence, \%) and area $\left(\mathrm{mm}^{2}\right)$. So far there are a very limited number of studies performed with this feature.

3.2. Laser-Induced Fluorescence. The DIAGNOdent (KaVo, Biberach, Germany) is a portable commercially available device (Figure $4(\mathrm{a})$ ) for detection and quantification of caries $[28,58]$. The method generates a simple numerical index of de- and remineralisation in enamel and dentin that can be recorded in the patient's file and monitored over time. The instrument is easy to handle and can also be purchased at a reasonable price. Red laser light $(\lambda=655 \mathrm{~nm})$ is emitted by the device via an optical fibre and a probe to the caries lesion (Figure 4(b)). When the light interacts with certain organic molecules that have been absorbed into the porous structure the light is reemitted as invisible fluorescence in the NIR region. The NIR fluorescence is believed to originate from protoporphyrin IX and related metabolic products of oral bacteria $[28,59]$ : these products are chiefly responsible for the absorption of red light. The emitted light is channelled through the hand piece to the detector and digitally displayed on a screen (0-99). A higher number indicates greater fluorescence and by inference a more extensive subsurface lesion.

Two versions of the laser fluorescence (LF) device are currently available commercially. As well as the DIAGNOdent 2095 for application to smooth and occlusal surfaces, the latest version, the LF-pen ( $\mathrm{KaVo})$, has been designed for easier access to approximal surfaces. The original LF device has shown good performance and reproducibility for detection and quantification of occlusal and smooth surface caries lesions in in vitro studies, but the results of in vivo studies have been somewhat contradictory [6070]. Among LF studies there is a wide variation in specific design features (the number of teeth included, the threshold for LF scores, validation methods, nonvalidated teeth, the outcomes expressed, etc.). A review by Bader and Shugars [24] disclosed that although several evaluations of diagnostic performance have appeared in the literature, the range of the LF device performances is extensive. For detection of dentinal caries, sensitivity values ranged widely (0.19 to 1.0$)$ although most tended to be high. Specificity values exhibited a similar pattern, ranging from 0.52 to 1.0. In comparison with visual assessment methods, the LF exhibited a sensitivity value that was almost always higher and a specificity value that was almost always lower. The body of evidence was based primarily on in vitro studies. Extrapolation to the clinical setting is uncertain.

The LF pen has performed as well as the original device on occlusal surfaces in vitro [71]. To date, there is only one published study of the clinical performance of the LF pen on occlusal surfaces [72]. A moderately positive correlation (Spearman rho) was demonstrated, and greater variation of measurements was recorded with increasing clinically evaluated lesion depth. At a cut-off value of 25 for the threshold between enamel and dentinal caries, sensitivity was 0.67 and specificity was 0.79 .

The LF method has also been investigated for longitudinal monitoring of the caries process and for assessing the outcome of preventive interventions [50, 63, 73-75]. The potential role of the LF device in detection of root caries lesions has not been extensively investigated and hitherto only three validity studies are available [76-78]. A low to moderate correlation was found when LF readings were correlated with histopathological lesion depth of root caries lesions $[76,77]$.

For the clinician to have confidence in using a caries detection method to support clinical treatment decisions, it is important that interpretation of readings is based on an understanding of the principles underlying the method and an awareness of potential shortcomings. With reference to LF, the question of what the method really measures has yet to be resolved. More research is needed to clarify the origin of the increased fluorescence caused by the excitation of $655 \mathrm{~nm}$ wavelength light. The NIR fluorescence is believed to originate from bacteria or their metabolites. Hence, there 


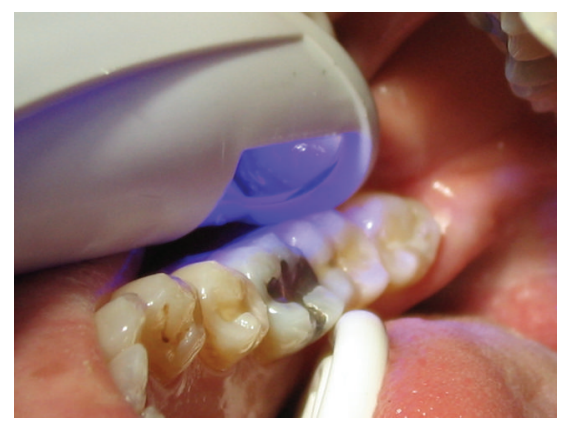

(a)

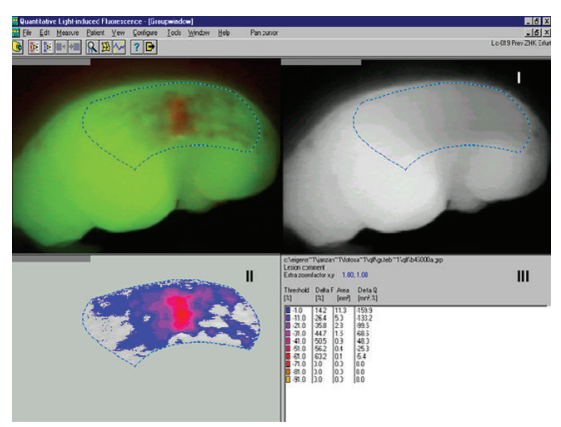

(b)

FIgURE 3: (a) Light of certain wavelengths is led by an optic fibre from the light source to a hand piece with a micro-Charge Couple Device video camera. (b) The image can be captured and saved for later analysis. Computer program: QLF 1.97e Inspector Research System BV, Amsterdam, The Netherlands.

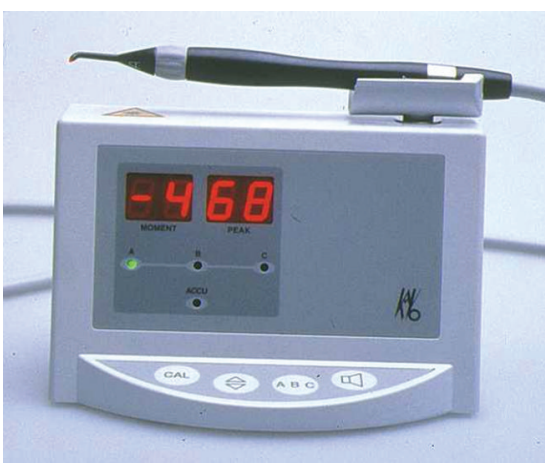

(a)

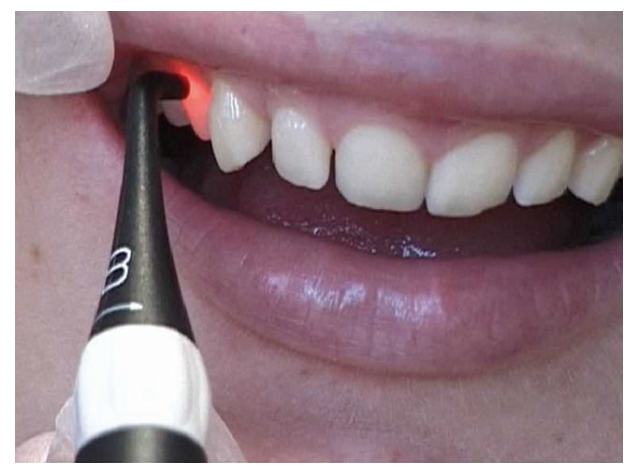

(b)

Figure 4: (a) The LF device operates with light from a diode laser transmitted through a descendent optic fibre to a hand held probe with a fibre optic eye. The emitted fluorescence is collected through the tip, passes into ascending fibres, and is finally processed and presented on the display as an integer between 0 and 99. (b) In the presence of carious tooth substance, fluorescence increases.

is a poor correlation between LF readings and the mineral content, but possibly better correlation with the presence of infected dentin.

In general, in vivo studies of LF for occlusal caries detection indicate moderate to high sensitivity and lower specificity $[24,60,66,68]$. Lack of specificity, the increased likelihood of false-positive readings due to stain and plaque, and the absence of a single threshold are factors underlying the reluctance among authors to recommend the LF method unequivocally for caries detection. Therefore, the LF device should be regarded at most as a supplementary aid for detection of caries on coronal surfaces.

3.3. Transillumination with Near-Infrared Light. The caries lesion may also be examined by shining white light through the tooth. Wavelengths in the visible range $(400-700 \mathrm{~nm})$ are limited by strong light scattering, making it difficult to image through more than $1 \mathrm{~mm}$ or $2 \mathrm{~mm}$ of tooth structure [79]. Therefore, methods employing wavelengths in the visible range of the electromagnetic spectra $(400-700 \mathrm{~nm})$ such as QLF [40] $(\lambda>520 \mathrm{~nm})$, LF [58] $(\lambda=655 \mathrm{~nm})$, and Digital Imaging Fiber-Optic Transillumination (DIFOTI) [80]which uses high intensity white light-are highly limited by scattering. Methods that use longer wavelengths, such as in the NIR spectra (780 to $1550 \mathrm{~nm}$ ), can penetrate the tissue more deeply. This deeper penetration is crucial for the transillumination (TI) method. Research has shown that enamel is highly transparent in the NIR range $(750 \mathrm{~nm}$ to $1500 \mathrm{~nm}$ ) due to the weak scattering and absorption in dental hard tissue at these wavelengths [81-86]. Therefore, this region of the electromagnetic spectrum is ideally suited to the development of new optical diagnostic tools based on TI. Figure 5 illustrates the typical experimental set-up of a TI system with an NIR light source, an imaging camera such as a charge-coupled device (CCD), and software for computercontrolled acquisition. The image can be captured, saved, and stored in digital format.

This is a promising imaging technique for detecting the presence of caries and measuring its severity. The TI image is presented as a visually recognizable image, which is preferred by the average clinician. The method is nondestructive, nonionising, and reportedly more sensitive to detect early demineralisation than dental $X$-rays [83]. Identification of dental caries by TI is based on the fact that increased mineral loss in an enamel lesion leads to a twofold increase in scattering coefficient at a wavelength of 


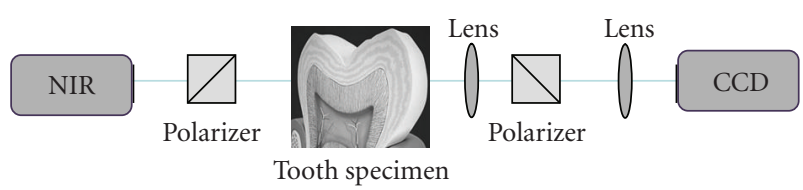

Figure 5: Transillumination (TI) with Near-Infrared (NIR) light. experimental set-up of the TI system. The tooth is illuminated with NIR light. Polarizers are used to experimentally block out the ambient light from saturating the detector, a Charge Couple Device (CCD).

$1.3 \mu \mathrm{m}[82,83]$. Caries thus appear as dark regions, since less light reaches the detector. Most research to date has used this wavelength, where low-cost light sources are available. When light illuminates the tooth the strong scattering effect in the enamel caries lesion results in less transparency. The decreased light transmission associated with the lesion can be detected when compared to that of the surrounding sound tissue.

The use of dental radiography should always be limited, even though it is the most often employed concept of routine examination. Dental radiographs also lack the sufficient ability for early caries detection $[13,16]$. An initial caries lesion may be missed or underestimated in size in radiographs due to low attenuation of radiation in lesion, particular physical properties of the tooth structure, and imperfect technique such as overlapping. In contrast, the TI method offers the advantage of allowing for repeated projection to overcome some of these limitations.

The importance of the location of the caries lesion and how the resolution differs when the resultant image has to traverse a thick part versus a thinner part of the tooth to reach the detector is also of interest. Contrast calculation of the signal generated by a single lesion located near versus far from the CCD camera can be estimated. The ratio between the contrasts of images captured from both sides of the tooth can estimate the more precise location of the caries lesion on the approximal surface.

\section{Summary}

Both QLF and the TI methods enable imaging detection of enamel caries that can be digitally stored and viewed later. The QLF method also includes image analysis software which measures the difference in fluorescence between sound and demineralised enamel. Changes in fluorescent radiance and lesion area can be followed over time, to measure lesion development. The method seems to have been rapidly adopted as a standard reference measure in clinical tests of the efficacy of preventive measures.

Transillumination of enamel with NIR light is a promising technique for the detection and imaging of occlusal and approximal lesions. Application of repeatable, nonionising radiation of the tooth allows the TI method to be used without restriction to monitor the caries process. The method overcomes some of the limitations of dental radiography such as overlapping. Moreover, the method can indicate the relative position of a lesion on approximal surfaces by calculating the ratio of contrast values obtained by illuminating tooth from the lingual or buccal surface, respectively. The method uses a range of wavelengths where low-cost light sources are available and the transmitted image can be detected by an ordinary CCD camera, similar to the one in mobile phones. The method can therefore be developed at reasonable cost as a fibre optic probe for intraoral use, connected to an ordinary computer screen.

The LF method generates a simple numerical index of de- and remineralisation in enamel and dentin that can be recorded in the patient's file and monitored over time. The instrument is easy to handle and can also be purchased at a reasonable price. New methods should be critically appraised according to strict criteria. Among LF studies there is a wide variation in specific design features (the number of teeth included, the threshold for LF scores, validation methods, the outcomes expressed, etc.). In vivo studies highlight the importance of rigorous clinical studies to confirm promising laboratory results. Results of the LF method in vivo have been somewhat contradictory. Therefore, The LF device should be regarded at most as a supplementary aid for detection of caries on coronal surfaces, pending the publication of further clinical studies.

\section{References}

[1] P. E. Petersen, D. Bourgeois, H. Ogawa, S. Estupinan-Day, and C. Ndiaye, "The global burden of oral diseases and risks to oral health," Bulletin of the World Health Organization, vol. 83, no. 9, pp. 661-669, 2005.

[2] I. Mejare, H. Stenlund, and C. Zelezny-Holmlund, "Caries incidence and lesion progression from adolescence to young adulthood: a prospective 15-year cohort study in Sweden," Caries Research, vol. 38, no. 2, pp. 130-141, 2004.

[3] J. D. B. Featherstone, "Dental caries: a dynamic disease process," Australian Dental Journal, vol. 53, no. 3, pp. 286-291, 2008.

[4] O. Fejerskov and E. Kidd, Dental Caries: The Disease and Its Clinical Management, chapter 4, Blackwell Munksgaard, Copenhagen, Denmark, 2nd edition, 2008.

[5] L.-P. Choo-Smith, C. C. S. Dong, B. Cleghorn, and M. Hewko, "Shedding new light on early caries detection," Journal of the Canadian Dental Association, vol. 74, no. 10, pp. 913-918, 2008.

[6] B. Angmar-Mansson, "How to measure the effects of fluoride treatments in clinical trials? Assessment: modern versus traditional methods," Caries Research, vol. 35, no. 1, supplement 1, pp. 30-33, 2001.

[7] I. A. Pretty, "Caries detection and diagnosis: novel technologies," Journal of Dentistry, vol. 34, no. 10, pp. 727-739, 2006.

[8] R. H. Selwitz, A. I. Ismail, and N. B. Pitts, "Dental caries," The Lancet, vol. 369, no. 9555, pp. 51-59, 2007.

[9] J. D. Bader, D. A. Shugars, and A. J. Bonito, "A systematic review of the performance of methods for identifying carious lesions," Journal of Public Health Dentistry, vol. 62, no. 4, pp. 201-213, 2002.

[10] M. S. Hopcraft and M. V. Morgan, "Comparison of radiographic and clinical diagnosis of approximal and occlusal dental caries in a young adult population," Community 
Dentistry and Oral Epidemiology, vol. 33, no. 3, pp. 212-218, 2005.

[11] K. Ridell, H. Olsson, and I. Mejare, "Unrestored dentin caries and deep dentin restorations in Swedish adolescents," Caries Research, vol. 42, no. 3, pp. 164-170, 2008.

[12] The Swedish Council on Technology Assessment in Health Care, "Caries-diagnosis, risk assessment and non-invasive treatment," Tech. Rep. 510-39, 2008.

[13] J. Yang and V. Dutra, "Utility of radiology, laser fluorescence, and transillumination," Dental Clinics of North America, vol. 49, no. 4, pp. 739-752, 2005.

[14] D. G. Altman and J. M. Bland, "Diagnostic tests 1: sensitivity and specificity," British Medical Journal, vol. 308, no. 6943, p. 1552, 1994.

[15] The Swedish Council on Technology Assessment in Health Care, "Karies_-diagnostik, riskbedömning och icke-invasiv behandling," no. 188:84, 2007.

[16] J. D. Bader, D. A. Shugars, and A. J. Bonito, "Systematic reviews of selected dental caries diagnostic and management methods," Journal of Dental Education, vol. 65, no. 10, pp. 960968, 2001.

[17] I. A. Pretty and G. Maupome, "A closer look at diagnosis in clinical dental practice: part 5. Emerging technologies for caries detection and diagnosis," Journal of the Canadian Dental Association, vol. 70, no. 8, pp. 540a-540i, 2004.

[18] G. K. Stookey and C. Gonzalez-Cabezas, "Emerging methods of caries diagnosis," Journal of Dental Education, vol. 65, no. 10, pp. 1001-1006, 2001.

[19] G. Stookey, Proceedings of the First Annual Indiana Conference: Early Detection of Dental Caries, Indiana University School of Dentistry, Indiana, Ind, USA, 1996.

[20] G. Stookey, Proceedings of the Second Annual Indiana Conference: Early Detection of Dental Caries, Indiana University School of Dentistry, Indianapolis, Ind, USA, 2000.

[21] G. Stookey, Proceedings of the Third Annual Indiana Conference: Early Detection of Dental Caries, Indiana University School of Dentistry, Indianapolis, Ind, USA, 2004.

[22] B. Angmar-Mansson, S. Al-Khateeb, and S. Tranaeus, "Monitoring the caries process. Optical methods for clinical diagnosis and quantification of enamel caries," European Journal of Oral Sciences, vol. 104, no. 4, part 2, pp. 480-485, 1996.

[23] B. Angmar-Mansson and J. J. ten Bosch, "Advances in methods for diagnosing coronal caries-a review," Advances in Dental Research, vol. 7, no. 2, pp. 70-79, 1993.

[24] J. D. Bader and D. A. Shugars, "A systematic review of the performance of a laser fluorescence device for detecting caries," Journal of the American Dental Association, vol. 135, no. 10, pp. 1413-1426, 2004.

[25] J. D. Bader and D. A. Shugars, "The evidence supporting alternative management strategies for early occlusal caries and suspected occlusal dentinal caries," Journal of Evidence-Based Dental Practice, vol. 6, no. 1, pp. 91-100, 2006.

[26] A. Hall and J. M. Girkin, "A review of potential new diagnostic modalities for caries lesions," Journal of Dental Research, vol. 83, supplement 1, pp. C89-C94, 2004.

[27] L. Karlsson and S. Tranæus, "Supplementary methods for detection and quantification of dental caries," Journal Laser Dentistry, vol. 16, no. 1, pp. 8-16, 2008.

[28] A. Lussi, R. Hibst, and R. Paulus, "DIAGNOdent: an optical method for caries detection," Journal of Dental Research, vol. 83, supplement 1, pp. C80-C83, 2004.
[29] K. W. Neuhaus, C. Longbottom, R. Ellwood, and A. Lussi, "Novel lesion detection aids," Monographs in Oral Science, vol. 21, pp. 52-62, 2009.

[30] A. C. Pereira, H. Eggertsson, E. A. Martinez-Mier, F. L. Mialhe, G. J. Eckert, and D. T. Zero, "Validity of caries detection on occlusal surfaces and treatment decisions based on results from multiple caries-detection methods," European Journal of Oral Sciences, vol. 117, no. 1, pp. 51-57, 2009.

[31] G. K. Stookey, "Optical methods-quantitative light fluorescence," Journal of Dental Research, vol. 83, supplement 1, pp. C84-C88, 2004.

[32] S. Tranaeus, X.-Q. Shi, and B. Angmar-Mansson, "Caries risk assessment: methods available to clinicians for caries detection," Community Dentistry and Oral Epidemiology, vol. 33, no. 4, pp. 265-273, 2005.

[33] D. A. Young, "New caries detection technologies and modern caries management: merging the strategies," General Dentistry, vol. 50, no. 4, pp. 320-331, 2002.

[34] A. F. Zandona and D. T. Zero, "Diagnostic tools for early caries detection," Journal of the American Dental Association, vol. 137, no. 12, pp. 1675-1684, 2006.

[35] J. R. Zijp, "Optical properties of dental hard tissue," in Introduction, chapter 1, Groningen Rijksuniversiteit, Groningen, The Netherlands, 2001.

[36] H. C. Benedict, "A note on the fluorescence of teeth in ultraviolet rays," Science, vol. 67, no. 1739, p. 442, 1928.

[37] E. Borisova, T. Uzunov, and L. Avramov, "Laser-induced autofluorescence study of caries model in vitro," Lasers in Medical Science, vol. 21, no. 1, pp. 34-41, 2006.

[38] H. Bjelkhagen, F. Sundström, B. Angmar-Månsson, and H. Rydén, "Early detection of enamel caries by the luminescence excited by visible laser light," Swedish Dental Journal, vol. 6, no. 1, pp. 1-7, 1982.

[39] F. Sundström, K. Fredriksson, S. Montan, U. HafstromBjorkman, and J. Ström, "Laser-induced fluorescence from sound and carious tooth substance: spectroscopic studies," Swedish Dental Journal, vol. 9, no. 2, pp. 71-80, 1985.

[40] E. de Josselin de Jong, F. Sundström, H. Westerling, S. Tranaeus, J. J. ten Bosch, and B. Angmar-Mansson, "A new method for in vivo quantification of changes in initial enamel caries with laser fluorescence," Caries Research, vol. 29, no. 1, pp. 2-7, 1995.

[41] B. Angmar-Mansson and J. J. ten Bosch, "Quantitative lightinduced fluorescence (QLF): a method for assessment of incipient caries lesions," Dentomaxillofacial Radiology, vol. 30, no. 6, pp. 298-307, 2001.

[42] S. Tranaeus, S. Al-Khateeb, S. Bjorkman, S. Twetman, and B. Angmar-Mansson, "Application of quantitative light-induced fluorescence to monitor incipient lesions in caries-active children. A comparative study of remineralisation by fluoride varnish and professional cleaning," European Journal of Oral Sciences, vol. 109, no. 2, pp. 71-75, 2001.

[43] M. H. van der Veen and E. de Josselin de Jong, "Application of quantitative light-induced fluorescence for assessing early caries lesions," Monographs in Oral Science, vol. 17, pp. 144$162,2000$.

[44] S. Al-Khateeb, J. M. ten Cate, B. Angmar-Mansson, et al., "Quantification of formation and remineralization of artificial enamel lesions with a new portable fluorescence device," Advances in Dental Research, vol. 11, no. 4, pp. 502-506, 1997.

[45] R. Gmur, E. Giertsen, M. H. van der Veen, E. de Josselin de Jong, J. M. ten Cate, and B. Guggenheim, "In vitro quantitative light-induced fluorescence to measure changes in enamel 
mineralization," Clinical Oral Investigations, vol. 10, no. 3, pp. 187-195, 2006.

[46] R. Heinrich-Weltzien, J. Kuhnisch, M. Van der veen, E. de Josselin de Jong, and L. Stosser, "Quantitative lightinduced fluorescence (QLF) - a potential method for the dental practitioner," Quintessence International, vol. 34, no. 3, pp. 181-188, 2003.

[47] N. B. Pitts and J. W. Stamm, "International consensus workshop on caries clinical trials (ICW-CCT) - final consensus statements: agreeing where the evidence leads," Journal of Dental Research, vol. 83, supplement 1, pp. C125-C128, 2004.

[48] Y. Feng, W. Yin, D. Hu, Y. P. Zhang, R. P. Ellwood, and I. A. Pretty, "Assessment of autofluorescence to detect the remineralization capabilities of sodium fluoride, monofluorophosphate and non-fluoride dentifrices: a single-blind cluster randomized trial," Caries Research, vol. 41, no. 5, pp. 358-364, 2007.

[49] L. Karlsson, L.-E. Lindgren, K. Trollsas, B. Angmar-Mansson, and S. Tranaeus, "Effect of supplementary amine fluoride gel in caries-active adolescents. a clinical QLF study," Acta Odontologica Scandinavica, vol. 65, no. 5, pp. 284-291, 2007.

[50] O. Kronenberg, A. Lussi, and S. Ruf, "Preventive effect of ozone on the development of white spot lesions during multibracket appliance therapy," Angle Orthodontist, vol. 79, no. 1, pp. 64-69, 2009.

[51] I. A. Pretty, J. A. Tavener, D. Browne, D. S. Brettle, H. Whelton, and R. P. Ellwood, "Quantification of dental fluorosis using fluorescence imaging," Caries Research, vol. 40, no. 5, pp. 426434, 2006.

[52] M. A. Ablal, J. S. Kaur, L. Cooper, et al., "The erosive potential of some alcopops using bovine enamel: an in vitro study," Journal of Dentistry, vol. 37, no. 11, pp. 835-839, 2009.

[53] V. Elton, L. Cooper, S. M. Higham, and N. Pender, "Validation of enamel erosion in vitro," Journal of Dentistry, vol. 37 , no. 5 , pp. 336-341, 2009.

[54] A. A. Adeyemi, N. Pender, and S. M. Higham, "The susceptibility of bleached enamel to staining as measured by Quantitative Light-induced Fluorescence (QLF)," International Dental Journal, vol. 58, no. 4, pp. 208-212, 2008.

[55] A. A. Adeyemi, F. D. Jarad, E. de Josselin de Jong, N. Pender, and S. M. Higham, "The evaluation of a novel method comparing quantitative light-induced fluorescence (QLF) with spectrophotometry to assess staining and bleaching of teeth," Clinical Oral Investigations, vol. 14, no. 1, pp. 19-25, 2010.

[56] A. M. Taylor, R. P. Ellwood, I. A. Pretty, and N. Mohan, "Quantitative stain detection in vivo using fluorescent imaging," Journal of Dentistry, vol. 37, no. 5, pp. 397-405, 2009.

[57] M. H. van der Veen, R. Z. Thomas, M. C. Huysmans, and J. J. de Soet, "Red autofluorescence of dental plaque bacteria," Caries Research, vol. 40, no. 6, pp. 542-545, 2006.

[58] R. Hibst and R. Gall, "Development of a diode laser-based fluorescence caries detector," Caries Research, vol. 32, no. 4, article 294, 1998.

[59] H. V. Gostanian, Z. Shey, C. Kasinathan, J. Caceda, and M. N. Janal, "An in vitro evaluation of the effect of sealant characteristics on laser fluorescence for caries detection," Pediatric Dentistry, vol. 28, no. 5, pp. 445-450, 2006.

[60] C. Abalos, M. Herrera, A. Jimenez-Planas, and R. Llamas, "Performance of laser fluorescence for detection of occlusal dentinal caries lesions in permanent molars: an in vivo study with total validation of the sample," Caries Research, vol. 43, no. 2, pp. 137-141, 2009.
[61] S. Akarsu and H. Koprulu, "In vivo comparison of the efficacy of DIAGNOdent by visual inspection and radiographic diagnostic techniques in the diagnosis of occlusal caries," Journal of Clinical Dentistry, vol. 17, no. 3, pp. 53-58, 2006.

[62] V. Angnes, G. Angnes, M. Batisttella, R. H. M. Grande, A. D. Loguercio, and A. Reis, "Clinical effectiveness of laser fluorescence, visual inspection and radiography in the detection of occlusal caries," Caries Research, vol. 39, no. 6, pp. 490-495, 2005.

[63] V. Anttonen, L. Seppa, and H. Hausen, "A follow-up study of the use of DIAGNOdent for monitoring fissure caries in children," Community Dentistry and Oral Epidemiology, vol. 32, no. 4, pp. 312-318, 2004.

[64] A. Astvaldsdottir, W. P. Holbrook, and S. Tranaeus, "Consistency of DIAGNOdent instruments for clinical assessment of fissure caries," Acta Odontologica Scandinavica, vol. 62, no. 4, pp. 193-198, 2004.

[65] M. Bamzahim, A. Aljehani, and X.-Q. Shi, "Clinical performance of DIAGNOdent in the detection of secondary carious lesions," Acta Odontologica Scandinavica, vol. 63, no. 1, pp. 2630, 2005.

[66] C. H. Chu, E. C. M. Lo, and D. S. H. You, "Clinical diagnosis of fissure caries with conventional and laser-induced fluorescence techniques," Lasers in Medical Science, pp. 1-8, 2009.

[67] M. A. Khalife, J. R. Boynton, J. B. Dennison, P. Yaman, and J. C. Hamilton, "In vivo evaluation of DIAGNOdent for the occlusal dental caries," Operative Dentistry, vol. 34, no. 2, pp. 136-141, 2009.

[68] A. Reis, F. M. Mendes, V. Angnes, G. Angnes, R. H. M. Grande, and A. D. Loguercio, "Performance of methods of occlusal caries detection in permanent teeth under clinical and laboratory conditions," Journal of Dentistry, vol. 34, no. 2, pp. 89-96, 2006.

[69] R. O. Rocha, T. M. Ardenghi, L. B. Oliveira, C. R. M. D. Rodrigues, and A. L. Ciamponi, "In vivo effectiveness of laser fluorescence compared to visual Inspection and radiography for the detection of occlusal caries in primary teeth," Caries Research, vol. 37, no. 6, pp. 437-441, 2003.

[70] S. Tranaeus, L.-E. Lindgren, L. Karlsson, and B. AngmarMansson, "In vivo validity and reliability of IR fluorescence measurements for caries detection and quantification," Swedish Dental Journal, vol. 28, no. 4, pp. 173-182, 2004.

[71] A. Lussi and E. Hellwig, "Performance of a new laser fluorescence device for the detection of occlusal caries in vitro," Journal of Dentistry, vol. 34, no. 7, pp. 467-471, 2006.

[72] K. C. Huth, K. W. Neuhaus, M. Gygax, et al., "Clinical performance of a new laser fluorescence device for detection of occlusal caries lesions in permanent molars," Journal of Dentistry, vol. 36, no. 12, pp. 1033-1040, 2008.

[73] A. Aljehani, M. Bamzahim, M. A. Yousif, and X. Q. Shi, "In vivo reliability of an infrared fluorescence method for quantification of carious lesions in orthodontic patients," Oral Health \& Preventive Dentistry, vol. 4, no. 2, pp. 145-150, 2006.

[74] A. Andersson, K. Skold-Larsson, A. Hallgren, L. G. Petersson, and S. Twetman, "Effect of a dental cream containing amorphous cream phosphate complexes on white spot lesion regression assessed by laser fluorescence," Oral Health \& Preventive Dentistry, vol. 5, no. 3, pp. 229-233, 2007.

[75] K. Skold-Larsson, A.-C. Fornell, A. Lussi, and S. Twetman, "Effect of topical applications of a chlorhexidine/thymolcontaining varnish on fissure caries assessed by laser fluorescence," Acta Odontologica Scandinavica, vol. 62, no. 6, pp. 339342, 2004. 
[76] L. Karlsson, E. Johansson, and S. Tranaeus, "Validity and reliability of laser-induced fluorescence measurements on carious root surfaces in vitro," Caries Research, vol. 43, no. 5, pp. 397-404, 2009.

[77] M. J. Wicht, R. Haak, H. Stutzer, D. Strohe, and M. J. Noack, "Intra- and interexaminer variability and validity of laser fluorescence and electrical resistance readings on root surface lesions," Caries Research, vol. 36, no. 4, pp. 241-248, 2002.

[78] W. Zhang, C. McGrath, and E. C. M. Lo, "A comparison of root caries diagnosis based on visual-tactile criteria and DIAGNOdent in vivo," Journal of Dentistry, vol. 37, no. 7, pp. 509-513, 2009.

[79] C. L. Darling and D. Fried, "Real-time near IR $(1310 \mathrm{~nm})$ imaging of CO2 laser ablation of enamel," Optics Express, vol. 16, no. 4, pp. 2685-2693, 2008.

[80] A. Schneiderman, M. Elbaum, T. Shultz, S. Keem, M. Greenebaum, and J. Driller, "Assessment of dental caries with digital imaging fiber-optic translllumination $\left(\mathrm{DIFOTI}^{\mathrm{TM}}\right)$ : in vitro Study," Caries Research, vol. 31, no. 2, pp. 103-110, 1997.

[81] C. M. Buhler, P. Ngaotheppitak, and D. Fried, "Imaging of occlusal dental caries (decay) with near-IR light at 1310-nm," Optics Express, vol. 13, no. 2, pp. 573-582, 2005.

[82] C. L. Darling and D. Fried, "Optical roperties of natural caries lesions in dental enamel at 1310-nm," in Lasers in Dentistry XI, P. Rechmann and D. Fried, Eds., vol. 5687 of Proceeding of SPIE, pp. 102-110, San Jose, Calif, USA, January 2005.

[83] C. L. Darling, G. D. Huynh, and D. Fried, "Light scattering properties of natural and artificially demineralized dental enamel at $1310 \mathrm{~nm}$," Journal of Biomedical Optics, vol. 11, no. 3, Article ID 034023, 2006.

[84] D. Fried, R. E. Glena, J. D. B. Featherstone, and W. Seka, "Nature of light scattering in dental enamel and dentin at visible and near-infrared wavelengths," Applied Optics, vol. 34, no. 7, pp. 1278-1285, 1995.

[85] R. S. Jones, G. D. Huynh, G. C. Jones, and D. Fried, "Nearinfrared transillumination at $1310-\mathrm{nm}$ for the imaging of early dental decay," Optics Express, vol. 11, no. 18, pp. 2259-2265, 2003.

[86] J. Wu and D. Fried, "High contrast near-infrared polarized reflectance images of demineralization on tooth buccal and occlusal surfaces at $\lambda=1310-\mathrm{nm}, "$ Lasers in Surgery and Medicine, vol. 41, no. 3, pp. 208-213, 2009. 


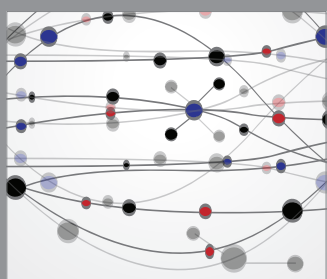

The Scientific World Journal
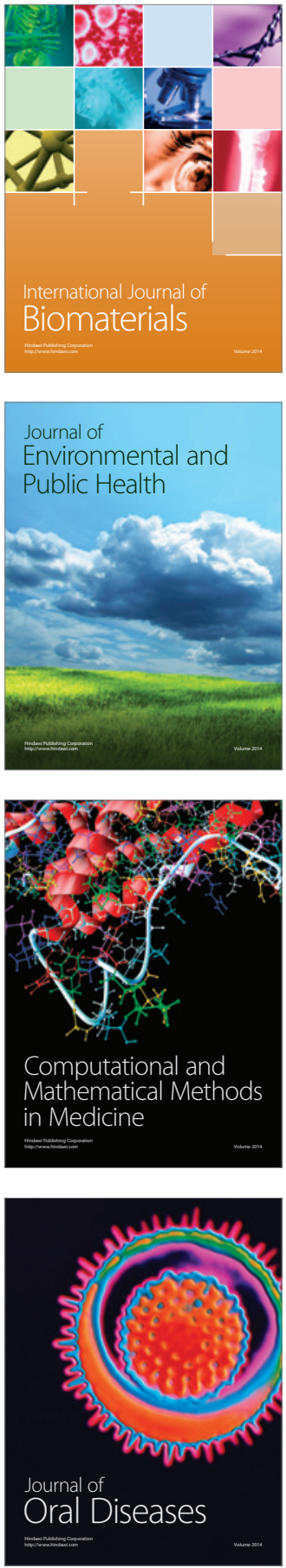
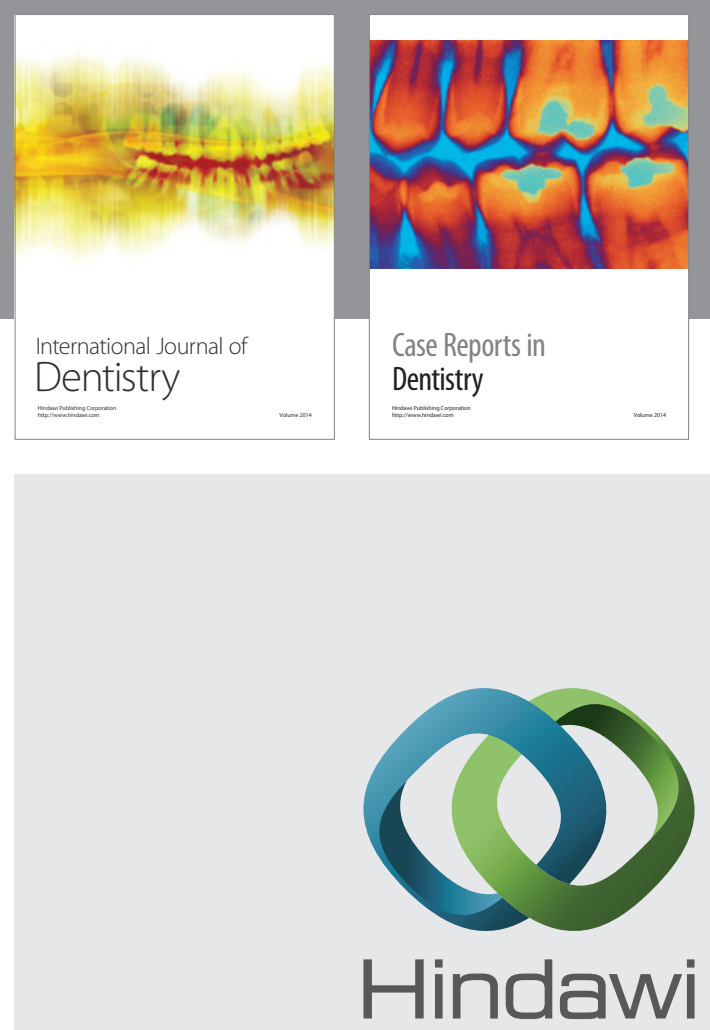

Submit your manuscripts at

http://www.hindawi.com
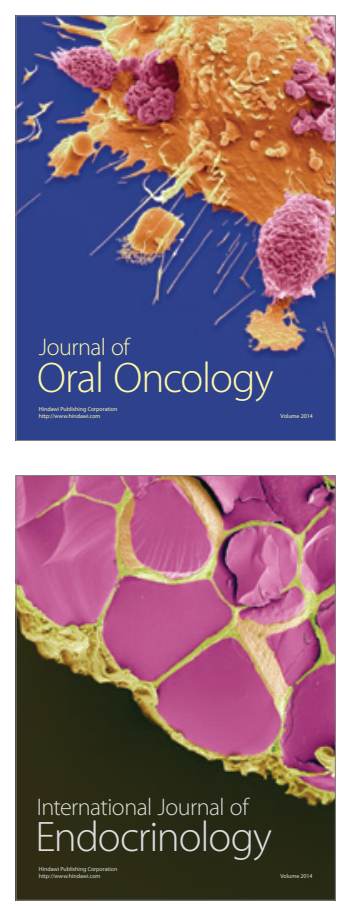
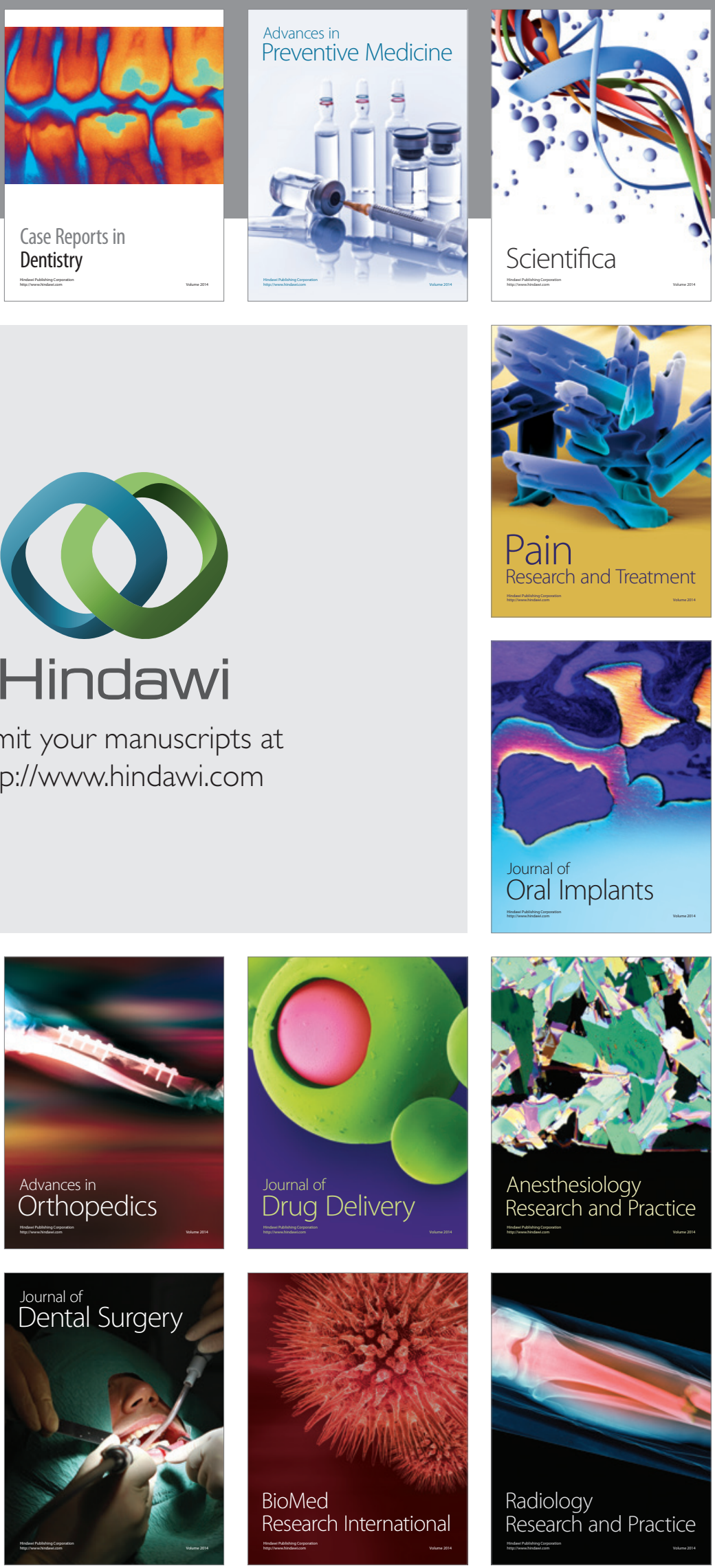